\title{
Renewing Cultural Resources and Sustaining J.H. Kwabena Nketia's Vision for an African Music Archive in Ghana
}

Dr. Colter Harper, Fulbright Scholar, Department of Music, University of Ghana

Judith Opoku-Boateng, Institute of African Studies, University of Ghana

DOI: https://doi.org//0.35320/ij.v0i50.10I

\begin{abstract}
This article examines the processes through which the J.H. Kwabena Nketia Archives has struggled to build a sustainable model for audio-visual archiving within an African university and looks to how its contents may serve future students and scholars in an effort to locate African cultural materials and knowledge production in Africa. The archive, operated within the University of Ghana's Institute of African Studies, was named in honor of Professor Nketia in 2015 and is the realization of over six decades of gathering audio and visual data, acquiring new collections, conducting research, and preservation efforts. The core collection of quarter-inch reels were recorded by Nketia in the early decades of his extensive career shaping Ghana's cultural policy, building teaching and research institutions, and studying music, culture, and language in Africa. As a part of the University of Ghana, the Nketia Archives provide a valuable resource for local students and scholars and creates a site in which broader conversations about the country's cultural legacies are brought into the socio-political discourse. The archive is also a resource for housing and making available new acquisitions including over 300 recently digitized recordings of Ghanaian popular music from professor John Collins' Bokoor African Popular Music Archives Foundation (BAPMAF). With ongoing challenges in accessibility, the Nketia Archives provides a valuable case study for how an African audio-visual archive is created and sustained.
\end{abstract}

We in the school of music and drama are deeply committed to African culture, and more especially to the performing arts of Africa. We believe that African traditional arts should be recorded, they should be preserved, they should be studied. But we believe also that they should not merely be studied, recorded, preserved, but practiced as living art. We believe also that the art must develop and that the study of African traditions should inspire creative experiments in the African idiom.

J. H. Kwabena Nketia

1963 Institute of African Studies Convocation speech

\section{Introduction}

In 1952, four years into the establishment of the University College of the Gold Coast (now University of Ghana), the idea of unifying the nation through collecting and archiving Ghanaian musical resources was conceived by young Joseph Hanson Kwabena Nketia, then a research fellow in African Studies. With the financial support and guidance of the head of the Sociology Department, Kofi Abrefa Busia, Nketia collected hundreds of recordings in the following decade. These recordings now comprise the core of the J.H. Kwabena Nketia Archives, which is operated by the University of Ghana's Institute of African Studies (IAS). The Archives, named in his honour in 2015, is the second largest audio-visual collection of traditional music in Ghana after the Ghana Broadcasting Corporation (GBC) Archives and has grown from the efforts of over six decades of gathering audio and visual data, acquiring new materials, conducting research, and undertaking preservation efforts. The core holdings of the archive are approximately 480 quarter-inch reel-to-reel tapes of field record- 
ings collected throughout Ghana by or under the direction of Nketia from 1952 to the late 1970s. These recordings span a key moment for Ghana as an emerging nation and for the University of Ghana at Legon as a site for the study of African music, dance, and theater.

Nketia's work as a scholar included both building this collection of recordings that reflected a national cultural identity as well as shaping university institutions where Ghanaian performing arts could be studied and practiced. The 1963 quote above reflects Nketia's dedication to documenting and preserving African performing arts as part of the decolonization of higher education in Africa and Ghana's efforts in nation building. His dedication remained unwavering throughout his extensive career and would take form in his teaching, lectures, publications, and musical compositions as well as his establishment of the International Centre for African Music and Dance (ICAMD) in 1992. In his 2016 book Reinstating Traditional Music in Contemporary Contexts (written at the age of 94), Nketia reflected that this preservation work, while in service of scholarly study, was also "a political priority for promoting national integration and the consciousness of the African identity undermined by colonialism" (Nketia 2016, 56). With Nketia's passing in 2019, IAS continues to search for ways to realize his vision for the study of Ghana's performing arts while sustaining a site for knowledge production of African culture. His namesake archive continues the work in recording, preserving, promoting, and disseminating knowledge of traditional music, and this article aims to be part of this effort through building an awareness of its manifold activities.

What began as Nketia's fieldwork as a research fellow, grew to include the recordings collected by other Ghanaian scholars including Ephraim Amu as well as European and American scholars who came to conduct research on West African music and culture. These efforts were foundations of an Africanist musicology, which engaged African music as part of a "network of interweaving cultures" that include "not only musical traditions that must be safeguarded for posterity, but also those that need to be actively studied, documented, developed and promoted and contemporary context of application in the light of Africa's ideas and vision of its modernity" (Nketia 2016, 105). The Nketia Archives is presented here as a case study of the important yet extensive process of building and sustaining an audio-visual archive in Africa. The challenges as well as the long-term commitment of this work is apparent in the fact that it was not until 2014 that the recordings created in the 1950s and 1960s became accessible to researchers in a digital format. What follows is a survey of this path from an African musicologist-oriented collection of music in Ghana to acquisitions of newer collections and current efforts to preserve recordings. We look specifically at early fieldwork efforts of the 1950s and 1960s; subsequent acquisitions of the 1970s; the establishment of ICAMD; the professionalization of the archive; digitization efforts; and the recent acquisition of the Bokoor Studio collection.

\section{Early Fieldwork and Acquisitions (1952-1978)}

Nketia approached fieldwork as an opportunity to expand his own musical sensibilities and connections to a broader African culture that extended beyond his own upbringing as an Akan. As a curious observer, Nketia was fascinated by the musical distinctions between various linguistic groups yet always listened for commonalities and themes that might be realized later in his own creative work (Nketia 1994, 10). Fieldwork was a process of discovery for Nketia: of Ghana's physical and musical landscapes; his own emerging sensibilities as a composer; and the primary research questions that would drive his scholarship. His recordings, experiences, and notes contributed to foundational studies of African music including Funeral Dirges of the Akan People (1955), African Music in Ghana (1963), Folk Songs of Ghana (1963), and The Music of Africa (1974). 
A survey of the hundreds of reel-to-reel tapes that have been digitized from Nketia and his colleagues' early fieldwork efforts shows a wide sample of music from throughout Ghana's five regions. Mary Seavoy, a student of Nketia's during his time at UCLA, visited Ghana likely in the late 1970s and helped catalogue and further organize the quarter-inch reels into a system called AWG (Africa-West-Ghana). Categories within this system included Akan (234), Ewe (7I), Dangbe (36), Ga (30), Dagomba (26), Gonje (19), Sisalla (I6), Frafra (II), and popular music (29). Samples from these categories include: Akan drumming styles such as Adowa, Atumpan, Akcm, Fcntcmfrcm, Sikyi, and Kete; festivals such as Akwanmc in the Central Region and Sokpoe Festival in the Volta Region; puberty rite music; funeral dirges; women's Adenkum vocal groups; Christian choral groups; brass bands; guitar bands; Dagomba gonje and lunsa drumming; and gyil (xylophone) music of the Upper West Region. These early fieldwork recordings range in styles from live performances (in festival and funeral settings), to analytical recordings (in which individual parts were demonstrated), to interviews conducted in Twi and English. In addition to some descriptive information on the reel boxes, the recordings are accompanied by typed field logs, which frequently included the researcher's name, musician names, locations, years, song titles, and recording descriptions.

Notable among this early fieldwork are ten reels, recorded by Ephraim Amu, which include recordings of seperewa (Akan harp-lute) musicians Kwadwo Nsia, Kwaku Asuo, and Kwadwo Okoto of the Ashanti region.' These recordings exemplify the fieldwork methods, preservation efforts, research potential, and ongoing creative application of a fading musical tradition. The seperewa or sankuo ${ }^{2}$ practice had been in decline in Akan culture by the mid-20th century, possibly due to the guitar's growing popularity as the string instrument of choice. The seperewa's history reaches before the formation of the Ashanti confederacy in 1670 with European descriptions of it first appearing around that time. In one short interview, conducted in Twi with musician Kwadwo Nsia (Tape AWG-A-93) by Amu, Nsia discusses the instrument's origins, construction, tuning, and use in performance. In the following excerpt, Nsia explains the instrument's name ${ }^{3}$ :

\begin{tabular}{|c|c|}
\hline $\begin{array}{l}\text { Ephraim Amu: Wo sanku yi, wofre no } \\
\text { d } \varepsilon n ?\end{array}$ & $\begin{array}{l}\text { Ephraim Amu: This string instrument, } \\
\text { what do you call it? }\end{array}$ \\
\hline Kwadwo Nsia: Wofre no seperewa. & Kwadwo Nsia: It is called seperewa. \\
\hline $\begin{array}{l}\text { EA: Seperewa. Ad£n nti na wofre no } \\
\text { seperewa? }\end{array}$ & $\begin{array}{l}\text { EA: Seperewa. Why do you call it } \\
\text { seperewa? }\end{array}$ \\
\hline
\end{tabular}

I Nketia writes in his article "The Scholarly Study of African Music: A Historical Review" (Garland Encyclopedia of World Music: Africa) that Amu, while teaching at the University of Science and Technology in Kumasi, conducted several years of fieldwork throughout Ghana with the support of a Rockefeller Foundation grant. These tapes were deposited in both the University in Kumasi and Legon and likely include those currently held in the Nketia Archives.

2 According to Christaller's Dictionary of Fante and Asante Language ( 881 ), sankuo refers to a local "stringed musical instrument" as well as European string or polyphonic instruments such as the guitar, fiddle, violin, harp, harpsichord, piano, and organ.

3 Twi transcription and English translation by Patrick Osafo Adu. 
KN: Seperewa no, $\varepsilon$ ne s $\varepsilon$ nsamanfo no

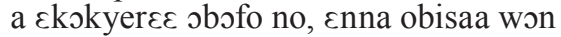
nanso na $\varepsilon y \varepsilon$ daeso nti wanhu won anim.

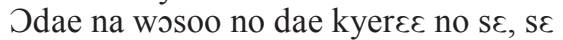
worep $\varepsilon$ a, wobehu. Woahu? Enna obisaa won $\mathrm{s} \varepsilon$, okwan ben na mefa so ahu? $\varepsilon$ nna

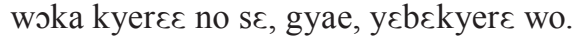
$\varepsilon$ no akyi no, ansa na woreyi akyer $\varepsilon$ no sønea wosi pam akaka yi ne cho nne nyinaa, na wose "pre."

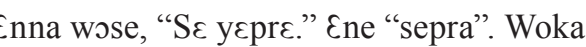

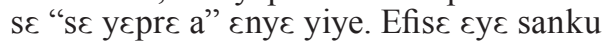

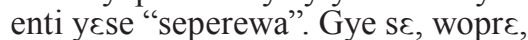
wode wo nsa na $\varepsilon$ pre na atumi aka asem.

EA: Wobos nsamamfo bi din na sanku yi

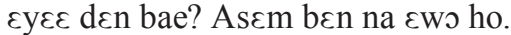

$\mathrm{KN}$ : The seperewa, [they say] it was ancestral ghosts who taught the hunter. It was in a dream that he met them so he didn't see their faces. He slept and saw them in a dream and they told him, "If you want to know, you will know." Then he asked them, "What path do I take to learn?" Then they told him, "Wait, we will teach you." It was later that they taught him how to make this box and all the things you see here, and the told him "pluck."

KN: Then they said, "when you pluck." That became "sepra". When you say "sj yjprj $a$ " it doesn't sound good. Because it is a string instrument, we say "seperewa." Unless you pluck, you use your hand to pluck [the strings] before it can speak/ communicate [sound].

EA: You mentioned some ghosts. What was their role with this instrument? Tell us more about it.

KN: Nea $\varepsilon m a a$ sanku no bae ne s $\varepsilon$ эbomm syerae. Onhu kwan mma fie. Jkstenaa dua bi adukuro mu...
$\mathrm{KN}$ : How it came about is that a hunter went to the forest to hunt but got lost and couldn't find the road to his house so he decided to rest under a large tree...

This interaction and the accompanying performances, while a valuable record of a fading performing arts tradition, also offers an intimate look into the fieldwork process as conducted by Amu. Conducting the interview in Twi allows for a conversational approach free of interruptions from translation since Amu is able to guide the conversation based on the information he is receiving. Amu's position as a cultural insider (Ghanaian and Twi speaker) and his status as an influential educator, scholar, and composer allow him to shift his role from curious student to experienced researcher to artist as he draws out folklore, asks technical questions about instrument construction, and discusses tuning techniques. The above conversation that emerged from Amu's question about the instrument's name reveals the importance of the origin story for Nsia. We learn that the instrument is associated with hunter culture, which invokes the importance of the similarly constructed donso ngoni for hunters in Burkina Faso. That the instrument originated from ancestral knowledge gained through communication with the spirit world grounds the practice in the Akan historical imaginary. When Amu pushes further to learn about the role of ancestral spirits, Nsia recounts a story in which a hunter becomes lost in the forest. While resting, the hunter hears the sound of an instrument which he follows but cannot locate. In his search, he reaches a road that leads him home though he remains eager to find the instrument that he had heard. It is only when he is visited in his dreams by ancestors that he is able to construct and play the instrument.

Nketia returned to these recordings in the early 1990s and published his article "Generative Processes in Seperewa Music" (1994) and wrote unpublished text transcriptions currently held in the Archives. As Nketia wrote, the seperewa, likely related to the Mandinka kora, became an important symbol in the early Ashanti nation. The first Ashanti king, Osei Tutu 
(I70I-I7) valued the instrument so highly that his successor King Opoku Ware (I720-50) had one built and covered in gold leaf to be included with the Golden Stool-the primary symbol of Ashanti identity and collectivity (Nketia 1994, 119). In an exemplary demonstration of how the archive should be the foundation for a living art, rather than a passive repository, Nketia hired seperewa master Osei Kwame Korankye in 1995 to contribute to ICAMD's research, teaching, and outreach activities while developing this fading tradition. Korankye continues to teach the instrument in the University of Ghana's Department of Music and also at Winneba College and performs extensively both in Ghana and abroad. As part of his evolving practice, Korankye has returned to Amu's field recordings in the development of his own approach to seperewa performance, which draws on his roots in Akan music and linguistic arts, experiences with Pan-African ensembles such Hewali Sounds and the Ghana Dance Ensemble, and collaborations with international artists.

From 1965 to 1979, Nketia directed IAS with continued dedication to fieldwork and preservation of Ghanaian performing arts. Nketia also pursued extended periods teaching abroad in ethnomusicology programs of UCLA (1969-1983) and the University of Pittsburgh (1983-199I). In 1975, IAS began implementing a five-year development plan that included establishing technical service units in photography, film, sound, and visual arts. The Photographic Unit documented cultural events such as festivals and other important traditional ceremonies. The Film Unit made ethnographic films and documentaries for teaching and archival purposes. The Visual Arts Unit collected Ghanaian and West African arts and crafts as the basis for establishing an IAS museum. The Sound Unit, tasked to amass materials that covered ethnomusicology and related fields, came to house the field research materials collected by Nketia and others. The recorded assets were managed by ethnomusicologist S. D. Asiamah and sound engineer Henaku Pobi. In the late 1970s, donations from sister institutions as well as research expeditions by other ethnomusicologists, fellows, staff and visiting researchers of IAS increased the archive's holdings. This included Mary Seavoy's research materials from Ife, Nigeria and Northern Ghana; Indiana University in Bloomington professor Ruth Stone's research materials labeled GhanaOwen Collection in the 1970s; and the British anthropologist Jack Goody's field research materials on Northern Ghana. In 1996, according to a report submitted by Dr. Asiamah to Professor Agovi, the then director of IAS, the IAS Sound Archive housed approximately one thousand records of 78, 45 and $33 \mathrm{I} / 3 \mathrm{rpm}$ shellacs and I,500 reel-to-reel tapes. ${ }^{4}$

\section{International Centre for African Music and Dance (ICAMD) (1992-2008)}

After retiring from the University of Pittsburgh, Nketia returned in 1992 to the University of Ghana to establish the International Centre for African Music and Dance (ICAMD). With support from the Ford Foundation, the Rockefeller Foundation, and Swedish International Development Agency (SIDA), Nketia created a research library from his personal collection, developed a program for gathering new documentation of Ghanaian performing arts, and hired resident artists to teach and perform. In a 1998 newsletter, he described ICAMD's aims:

4 Under Asiama, the collection was catalogued using an index system which was an alphabetic re-working of the Systematische Catalogus, devised by Bernard Broere of the Ethnomusicologisch, Archief, Institute Voor Muziekwetenschap, Universiteit Van Amsterdam. There were also card indexes which analysed the collection in terms of individual items, musical types, performers, instruments and societies (Asiamah 1996: 3). 
The challenges of the milieu to which I was returning after my sojourn in the US required that I do something different. ...I could inspire others to do field research instead of doing everything myself the way I used to do, encourage scholars and artists to make use of the archival materials I had already set up in the Institute of African Studies which could be enlarged through various modes of acquisition, develop a specialized "library" with my own collection of books and other materials as a base for a small institutional reference library, and share my knowledge, experience and reflections with others who might carry them forward, as we collectively confront the practical realities of music and dance in our changing African environment (ICAMD Newsletter 1998: I).

In the late 1990s, ICAMD served as a platform for encouraging scholars from the Music Department and the School of Performing Arts to conduct research trips and supplement Nketia's early recordings. ${ }^{5}$ Additionally, the Centre organized a lecture series and conferences on issues such as music therapy, music education, music composition, and established various institutional linkages through invitation to research fellows from Ivory Coast, Nigeria, Zambia, Tanzania, Congo, and Zimbabwe, who were given the opportunity to research in the Archives and work under Professor Nketia's personal supervision. ${ }^{6}$ Resident artist positions were created for promising young musicians including the aforementioned seperewa master Osei Korankye as well as atentenben virtuoso Dela Botri and his group Hewale Sounds, which became the ICAMD's performing group in residence. According to Nketia,

This idea of reaching out to others in the disciplines of music seemed to me appropriate for the situation in Africa where composers may be ethnomusicologists, music educators, cultural officers, members of arts organizations etc., multiple roles I had previously assumed myself. It has led me to redefine the subject areas of my field to include development studies in ethnomusicology with particular reference to African music and dance (ICAMD Newsletter, 1998: 2).

Within ten years, the ICAMD audiovisual archives, managed by archivist Maxwell Agyei Addo, was the most vibrant audiovisual archives on the University of Ghana campus, serving local and international students and faculty. This encouraged scholars affiliated with ICAMD to donate their research materials to the archive in order to support Nketia's vision and efforts. Donations included:

5 Some of these scholars included Professor Mawere Opoku, Dr. Willie Anku, Mr. Kosi Adom, Mr.T. E. Andoh, Mrs. Bertha Adom, Dr. Nissio Fiagbedzi, Dr. Asante Darkwa, and Miss Patience Kwakwa.

6 Some of these research fellows included Pascal Zabana Kongo, Josephine Mokwunyei, Robson Rudsvidzo, Prince Lamba, Herbert Makoye, Bridget Chinouriri, and Adepo Yapo. 


\begin{tabular}{|c|c|c|}
\hline Year & Source & Contents \\
\hline c. 1994 & Paul Neely & $\begin{array}{l}\text { Ghana Institute of Languages Literature and } \\
\text { Bible Translations (GILLBT) recordings of } \\
\text { church music in traditional singing styles }\end{array}$ \\
\hline 1994 & Catherine Melhorn & Collection of songs from Ghana - 1994 \\
\hline 1994 & Claudia Melrose & $\begin{array}{l}\text { Collection on dances and standard books on } \\
\text { dance and related fields }\end{array}$ \\
\hline 1995 & Patience Kwakwa & $\begin{array}{l}\text { Video recordings on dances in Ghana and other } \\
\text { parts of Africa }\end{array}$ \\
\hline c. 1996 & Mary Seavoy & $\begin{array}{l}\text { Audio and visual recordings, slides, and } \\
\text { photographs from Northern Ghana }\end{array}$ \\
\hline 1997 & $\begin{array}{l}\text { Mitchel Strumpf } \\
\text { and Gustav Oware } \\
\text { Twerefoo }\end{array}$ & $\begin{array}{l}\text { Audio and visual recordings of traditional music } \\
\text { and dance from Malawi and the Venda of South } \\
\text { Africa }\end{array}$ \\
\hline 1997 & $\begin{array}{l}\text { Sharon Katz and } \\
\text { Marilyn Cohen }\end{array}$ & Concerts in South Africa \\
\hline 1997 & Herbert F. Makoye & Field recordings from Sukumaland, Tanzania \\
\hline 1998 & Ceasar Ndlovu & Materials from Zululand, South Africa \\
\hline c. 1998 & Leo Sarkissian & $\begin{array}{l}\text { Leo Sarkissian's Voice of America's Time in } \\
\text { Africa recordings }\end{array}$ \\
\hline 1998 & Josephine Mokwunyei & 1998 recording from Ekpe, Nigeria \\
\hline 1999 & Jesse Shipley & Recording of Panafest 1999 \\
\hline 1999 & Kwasi Ampene & $\begin{array}{l}\text { Field research materials on Ashanti culture } \\
\text { (Nnownkor } \square \text { ) from } 1999\end{array}$ \\
\hline $\begin{array}{l}1996- \\
2000\end{array}$ & Mawere Opoku & $\begin{array}{l}\text { Video recordings of traditional dances, palace } \\
\text { ceremonies, funerals, and dance groups }\end{array}$ \\
\hline c. 2000 & Trevor Wiggins & $\begin{array}{l}\text { Audio and visual recordings from Nandom, } \\
\text { Sisaala, Lambussie and parts of Burkina Faso }\end{array}$ \\
\hline c. 2000 & Catherine Cole & $\begin{array}{l}\text { Donation of Melville Herskovits's 193I film } \\
\text { study of West Africa }\end{array}$ \\
\hline $\begin{array}{l}1999- \\
2010\end{array}$ & Dominik Phyfferoen & $\begin{array}{l}\text { Audio and visual recordings from the } \\
\text { DEKKMMA Project; fieldwork in the Northern } \\
\text { Region of Ghana from } 1999 \text { to } 2010\end{array}$ \\
\hline c. 2000 & Jacqueline Djedje & $\begin{array}{l}\text { Audio and visual recordings from Northern } \\
\text { Ghana }\end{array}$ \\
\hline c. 2000 & $\begin{array}{l}\text { Tervuren Museum and } \\
\text { colleagues in Zimbabwe }\end{array}$ & $\begin{array}{l}\text { The UNESCO collection of selected field } \\
\text { recordings from Africa }\end{array}$ \\
\hline
\end{tabular}


Despite the success in growing the invaluable collection of Ghanaian cultural heritage, the IAS Sound Archive lacked the resources to provide for the physical and administrative care of the recordings. Playback machines were in disrepair, the rooms in which the materials were kept were in bad shape, and worst of all, the materials were difficult to access. In 2003, African music scholar Kofi Agawu reflected on the seeming impossibility of "productive scholarship" on African music stemming from African libraries and archives:

...the archivist may not be seen for days, where the playback equipment, although visibly displayed, does not work, and where a request for a copy of this or that recording may be greeted by the suspicion that the scholar is going to make money with it. (How strange that the archivist and his staff have not sought to make money with these recordings all these years.) Then follows the invention of any number of excuses why a copy would be hard to make. (Dangling your wallet can work wonders on such occasions.) The archives are, in a sense, a microcosm of the difficulties that enshroud institutions in postcolonial Africa, difficulties that have led to a profound undervaluing of treasures that lie under our very noses (Agawu 2003, 35).

Recounting his frustrated attempts to access Nketia's recordings through the then "Archives of Recorded Sound at the Institute of African Studies," Agawu puts forth the possibility that "a precondition for significant and authentic contribution to scholarship may well be that the individual scholar leave Africa, if only temporarily. The archive of African music must therefore necessarily exist outside the continent's geographical and perhaps psychical boundaries. It must exist overwhelmingly in the hands of others, not Africans" (Agawu 2003, 35).

Taking into consideration such negative feedback, Nketia consulted IAS director Takyiwaa Manuh to merge the audiovisual collections at ICAMD and that of the old Sound Unit's archive of the IAS, so that the combined archive could be properly managed under new staff. In 2004, the audiovisual collection of ICAMD was moved and added to the IAS collection managed by ICAMD until 2008 when Nketia, who had until then been running ICAMD, handed the merged unit over to IAS and named it the IAS/ICAMD Audiovisual Archive. With this new institutional structure in place, there remained a need for managers and technicians to find ways to preserve and make these materials available. These developments were implemented largely through partnerships with New York University in the following decade.

\section{Professionalizing the Archive}

In May 20II, the Audiovisual Preservation Exchange (APEX), a research branch of New York University's Moving Image Archiving and Preservation (MIAP) programme, organized its annual training workshop for audiovisual heritage practitioners in Accra, Ghana. This workshop took place at the Ghana Broadcasting Corporation (GBC) and provided an important networking opportunity for the IAS/ICAMD Audiovisual Archive's Principal Research Assistant Judith Opoku-Boateng. ${ }^{7}$ The theme of the workshop was "Imagining

7 Opoku-Boateng won the Jim Lindner Prize for Cultural Heritage Preservation, which provided support to purchase a laptop and cataloguing software. 
Access to Audiovisual Heritage" and covered collection assessment, proposal writing, caring for collections, and metadata standards. ${ }^{8}$ A month later, the US State Department, through its embassy in Accra, nominated Opoku-Boateng for the International Visitor Leadership Programme (IVLP) on the theme of cultural heritage preservation. This programme, coupled with the APEX training, significantly enhanced the management practices at the Archive by demonstrating international standards of archival care and linking its staff to a network of professionals.

In February 2012, two of the NYU APEX team members, Mona Jimenez and Kara Van Malssen, returned to Ghana to inspect and assess the IAS/ICAMD Audiovisual Archive's assets and storage environments and produced a 65-page document titled University of Ghana: Audiovisual Collection Assessment and Digitization Plan. The report supported the University's vision of preservation and access of significant audiovisual materials and was submitted to IAS with copies distributed to collection managers, information technology specialists, and the decision-making bodies at the University. To further support the IAS-NYU collaborative effort, a two-month summer internship was developed for MIAP graduate student Kelly Haydon, a database specialist, as per the recommendations outlined in the collection assessment report. Haydon helped to customize the database to fit the archive's needs, worked with staff to create metadata standards, provided training, and assisted the archivist with promoting the database within the larger context of the University of Ghana (Opoku-Boateng 2014: 2).

In the meanwhile, Akosua Adomako Ampofo, the director of IAS, oversaw the creation of a full-time archivist position within IAS and appointed Opoku-Boateng in January 2013. Additionally, two former National Service Personnel at the Archive, George Gyasi Gyesaw and Nathaniel Worlanyo Kpogo, who had undergone training by the NYU/AVPS team, received long-term appointments. These appointments marked the first significant step in the professionalization of the archive as an important body within the institute. In recognition of the profound need for continued training and constant maintenance and improvement of collections standards, Opoku-Boateng was selected by the International Centre for the Study of the Preservation and Restoration of Cultural Property (ICCROM) in 2013 to attend the International Training Programme: SOIMA 20I3: Sustaining Sound and Image Collections. This programme equipped Opoku-Boateng with the requisite knowledge as the archive was embarking on an analogue to digital journey through the NYU/IAS collaborative project that year.

In 2013, Ampofo called for a proper restructuring of the Archives and in June 2014, the facility was expanded from two to seven rooms in order to properly house a storage for audiovisual records, IAS Paper Heritage Materials, and Arabic Manuscripts; an audio digitization laboratory; a listening station, cataloguing room, and reception; a classroom for group viewing or listening; an oral history cinematic studio and transcription room; and an office space for the archivist and staff. The renewed investment in the archives at IAS culminated in February 2015 when the institute named its new archive complex the J.H. Kwabena Nketia Archives. These efforts demonstrate the increasing awareness and embracing of the archive as a national resource and a common cultural treasure to be maintained in line with Nketia's vision of it as a place for the living arts of Africa.

8 APEX team members and included Mona Jimenez, Kara Van Malssen, Jennifer Blaylock, Ishumael Zinyengere. 
Donations which have been so far added to the collection in this facility include:

\begin{tabular}{|c|c|c|}
\hline Year & Source & Contents \\
\hline 2014 & $\begin{array}{l}\text { Prof. Mary Esther Dakubu } \\
\text { Kropp and Dr. Samuel } \\
\text { Ntewusu }\end{array}$ & $\begin{array}{l}\text { 20I2-20I3 Materials from ELDP funded } \\
\text { research project: "Vanishing Voices in Ghana's } \\
\text { Middle Belt" }\end{array}$ \\
\hline 2014 & Karl Haas & Field research materials from Northern Ghana \\
\hline 2015 & $\begin{array}{l}\text { Professor Esi Sutherland } \\
\text { Addy }\end{array}$ & $\begin{array}{l}\text { Afua Sutherland's audio recordings of concert } \\
\text { parties }\end{array}$ \\
\hline 2015 & Godwin Adjei & Field research materials on Ghanaian culture \\
\hline 2016 & Royal Hartigan & $\begin{array}{l}\text { Research materials and analytical books on } \\
\text { Ghanaian drumming }\end{array}$ \\
\hline 2017 & Kwabena Nketia & Published and unpublished personal papers \\
\hline 2017 & Kwasi Ampene & $\begin{array}{l}\text { Recordings of the burial and funeral rites } \\
\text { of Nana Afia Serwaa Kobi Ampem II (late } \\
\text { Asantehemaa) }\end{array}$ \\
\hline 2017 & Obadele Kambon & $\begin{array}{l}\text { Ritual performances in Ghana, Ghanaian } \\
\text { festivals, storytelling, musical performances, } \\
\text { etc. }\end{array}$ \\
\hline 2017 & Bertha Setor Adom & $\begin{array}{l}\text { Commercial recordings produced by Faisal } \\
\text { Helwani }\end{array}$ \\
\hline 2017 & Tobias Klein & $\begin{array}{l}\text { Documentary on “Life in Ghana After } \\
\text { Independence” produced in Germany }\end{array}$ \\
\hline 2018 & Alice Daniel & $\begin{array}{l}\text { Oral history interviews on political history of } \\
\text { Ghana with some Ghanaian journalists }\end{array}$ \\
\hline 2018 & Michael Vercelli & Field recordings from Northern Ghana \\
\hline 2018 & Egberto Bermudez & Recordings from Colombia \\
\hline 2018 & Janet Topp Fargion & $\begin{array}{l}\text { Digitized recordings of Robert Sutherland } \\
\text { Rattray Wax Cylinder Recordings on Akan } \\
\text { traditions, recorded in the 1920s and deposited } \\
\text { in the British Library }\end{array}$ \\
\hline 2019 & Austin Emielu & Personal collection of highlife and gospel music \\
\hline
\end{tabular}

As an independently staffed and managed institution, the Archives has facilitated further collaborations with outside institutions. In summer 2017, the International Centre for the Study of the Preservation and Restoration of Cultural Property (ICCROM) organized an international training workshop titled SOIMA 2017: Sustaining Sound and Image Heritage. Hosted by IAS, the Nketia Archives was presented as the case study for nineteen participants from twelve countries. In October 2018, IAS and the Nketia Archives hosted the 49th annual conference of the International Association of Sound and Audiovisual Archives (IASA). Over 150 attendees from more than 30 countries worldwide participated in this 
important meeting of educators, scholars, and technicians in West Africa. ${ }^{9}$ Such active participation in international professional gatherings has increased the awareness of the Archives as a key institution. Networking with peers from around the world, the Nketia Archives is becoming an encouraging case study to other under-resourced archives, and through collaborations and partnerships, it can remain open to future possibilities, especially in terms of increasing access to researchers from around the world.

\section{Contemporary Challenges of Accessibility and Digital Infrastructure}

The primary goal of any audiovisual archive is to both preserve and facilitate the access to its holdings, which has become synonymous with digitization in the last three decades. The first efforts to digitally transfer the quarter-inch reel recordings held by IAS were initiated during the 1987 meeting of the International Association for the Study of Popular Music (IASPM) held in Accra. It was during this conference that visiting scholars including the German musicologist Wolfgang Bender (University of Mainz) were taken on a tour of the University of Ghana and the fieldwork collection in IAS. Driven by the deteriorating conditions of the audiovisual materials, Bender coordinated efforts to digitize the reels with professor Simeon Asiama of IAS, and, after securing support from the cultural department of the German Foreign Office, began the process in 1993. Working with Asiama, John Collins (technical assistant), Henaku Pobi, and Victoria Honu, Bender oversaw the transfer of approximately 480 reels onto two sets of Digital Audio Tapes (DATs).

This project lasted eight months during which time the reels were transferred onto two sets of DAT. The first set of tapes stayed with IAS and the second set of "safety copies" was transferred to the newly established African Music Archive (AMA) housed in the Johannes Gutenberg University in Mainz, Germany (Bender 1994, 156). In a recent email correspondence with the authors, current AMA director Dr. Hauke Dorsch confirmed that these DATs left the collection with Bender upon his retirement as director in 2008 but have been returned in July, 2019. To date, these recordings have not been digitized by the AMA though Bender did released a commercial CD titled Music in Ghana (1997), made up of selections from the Nketia collection.

As for the first set of DATs held at the Nketia Archives, they proved impractical for the rapidly changing needs of the twenty-first century archive. Though the DATs were technically in a digital format, they still required real time transfer to be stored on a hard drive or online. With a growing partnership with NYU's APEX team, the Nketia Archives began devising a digitization plan that ultimately involved a direct transfer from the original reels. In July 2014, the Nketia Archives, with its newly appointed staff and management at helm, welcomed back APEX to execute the long overdue audio digitization project, with the following goals: "build capacity for archival quality digitization at the IAS Audio-Visual Archive; create broad access and ensure digital preservation of the newly created digital assets; promote Ghana's rich sound heritage by facilitating new uses of these materials for teaching, learning, scholarship, production and application" (APEX).

The first phase of the project was the setting up of an audio digitization laboratory and designing the workflow for the files to be safely stored in the University's servers. The project provided hands-on training in audio preservation and digitization for the now long-

9 Countries represented at the conference include: Ghana, United Arab Emirates, Latvia, South Africa, Australia, Taiwan, China, Belgium, Sweden, Portugal, Ireland, Portugal, Thailand, India, Czech Republic, United Kingdom, United States of America, Malawi, New Zealand, Italy, Norway, Switzerland, Australia, Israel, France, and Japan. 
term staff of the Archives. Additionally, it combined old and new technology - techniques needed to dry out and clean mold on the tapes so that they may be played - and the latest methodologies for capture of the content and metadata that allows for discovery, use, and sustainability. Since August 2014, the Archives has physically preserved and digitized over five hundred hours of traditional music, oral histories, and indigenous cultures recorded on quarter-inch reels. The recorded assets are accessible at a listening station at the Archives, and preservation masters have been stored on University of Ghana's Computing System's Storage Environment. Access to this directory is limited to the UGCS administrators and the logins of key staff, while patron access remains restricted at this stage. ${ }^{10}$

The project has created a model for other sound and image heritage preservation institutions in the country and across the globe as a successful example of a partnership that has left a long-term, positive impact on an under-resourced archive in need of professional training and start-up support required in large-scale digitization efforts. The challenges to preserving and researching African music in African institutions are immense and magnified in a digital environment. Agawu's 2003 indictment of the Archive's management at that time serves as a benchmark measuring recent progress and development and also offers a glimpse of how valuable materials, though located in Africa, require an extensive network of like-minded specialists to be accessed.

With scholars in African universities lacking resources to access European and American archives, majority of the current scholarship on African music in major journals is produced abroad. Problems compound to create a unique challenge for preserving and accessing historical audio-visual documents in Africa. The lack of local funding towards training, storage, climate control, equipment purchases and maintenance, and digitization create an environment where valuable materials face deterioration. Challenges to building digital platforms and providing physical space for reviewing materials also limit access and potential utility of collections. Beyond these technical problems, there remain prickly questions of copyright around the use and representation of living folklore.

The picture of audiovisual archives in Africa reveals a great need for varied technical and management skills as well as a context in which cultural documents are accessible for researchers. Archivist Nathan Mnjama notes that many audiovisual collections in Botswana are overseen by librarians who have the training to catalog and process materials but lack the knowledge and equipment to repair damaged materials and digitize older recording mediums (Mnjama 20I0). In another case, audiovisual archivist Ishumael Zunyengere paints a bleak picture of the challenges faced by Zimbabwe's national archives in 2008 in the larger scope of the country's state of welfare:

The humanitarian, social and political crisis is of immense proportions. Most significantly in the past months lives have been lost through disease, starvation and acute economic decay. Our main hospitals of Parirenyatwa and Harare Main Hospital have now been effectively closed down in some wings because of the lack of medicines and staff. With these problems government reverts all its attention to the humanitarian crisis

10 The IAS stores a local copy of the digital files on the RAID 5 array, that is in the audio lab. The UGCS creates and maintains an offline backup copy of the data. The IAS Archive network is connected to the fibre backbone, via dual gigabyte connectivity to allow appropriate throughput of data which is sometimes transferred in bulk. Digitized data per year is estimated at 1.5 Terabyte, or 125 Gigabyte per month. 
and the National Archives is left with less funds to just keep it running. The audiovisual heritage is therefore left to the Archivist to find ways of conserving the materials using the resources available (Zinyengere 2008, 38).

While Ghana has not suffered comparable economic collapse and social hardships experienced in Zimbabwe, archival efforts have met with many of the common challenges in building a sustainable audio-visual archive in an under-funded context. While the partnership with NYU has lent an enormous platform for furthering the work of the Nketia Archives, one-off or even intermittent collaborative projects must be supplemented with a long-term engagement with local scholars and students who embrace their role as advocates and active contributors and users of the Archives.

\section{The Bokoor Studios Acquisition (2019)}

The Nketia Archives is an open archive, continuing its acquisition activities in its ongoing efforts to build a fuller picture of Ghana's musical heritage. Of the recent acquisitions, the following case demonstrates the work being done by the Archives to ensure sustained growth and utility for researchers and students. The archives' most recent acquisition includes materials from professor John Collins' Bokoor African Popular Music Archives Foundation (BAPMAF), which is comprised of photographs and commercial recordings collected and produced by Collins throughout the 1970s and 1980s. In addition to his work as a researcher, Collins operated a recording studio from his home in Taifa on the outskirts of Accra from mid-198I to around 1994. During this period Collins acted as producer and engineer for approximately 250 recording sessions of popular, traditional, and gospel music from Ghana. These sessions were recorded on a Tascam four-track Portastudio, which offered the least expensive and most portable means to multitrack recording in the 1980s. The Portastudio revolutionized entry-level recording by using the inexpensive cassette tape as a medium though running the tape at double speed to increase sound quality. The machine had four microphone inputs which could be assigned to four separate tracks. These four tracks were mixed to a stereo recording, which could be duplicated for local markets. Collins' innovative use of the Portastudio enabled him to produce professional recordings including up to nine instrumentalists and vocalists. From the approximately 500 cassettes that Collins used during these sessions, about 290 have survived and contain approximately 90 hours of four-track recordings.

In the spring of 2019 , these tapes were digitized by ethnomusicologist Colter Harper in a collaborative project with John Collins and the Nketia archives with the goal of making them available for research. A small percentage of these recordings have already appeared as international LP releases with subsequent streaming released. These including The Guitar and the Gun (Africagram Records, 1983), The Guitar and the Gun II (Africagram Records, 1985), N'Tutu by the Genesis Gospel Singers (Africagram Records, 1984), Electric Highlife: Sessions from the Bokoor Studios (Naxos World, 2002), and Kukurantumi by Amertey Hedzoleh (Chop Time Music, 2014). Other recordings were released near the time of recording on the Ghanaian LP and cassette market but have become difficult to locate due to the disappearance of cassette shops. The value of this rare collection is apparent in the intimate look it offers into the musical life of Ghana under the military government of Jerry Rawlings (1982-1993), a period when live music was greatly curtailed under the military curfew enforced from 1982 for about three years. The collection also documents Collins' practice as a music producer, which remains an ill-addressed side of his career as a contributor to the popular music in West Africa. 
The addition of this collection of materials significantly updates the Nketia Archives holdings by filling in a big gap in the chronology of musical history of Ghana. In Nketia's footsteps as an active researcher, Collins' recordings provide yet another model of scholarly research that can inspire future work among the users of the Archives. Currently, Harper and Collins are working to contact artists from the recordings and collect oral history relating to the experiences of musicians in Rawlings era Ghana. These stories will provide a detailed look at the creative lives of popular musicians during a pivotal decade in which new technologies dramatically changed how music was produced, performed, and consumed.

\section{Conclusion}

There is a growing support for Africa's right to determine and preserve its cultural heritage as exemplified in the 2018 report The Restitution of African Cultural Heritage: Toward a New Relational Ethics by Felwine Sarr and Bénédicte Savoy, which calls for a sweeping new relational ethics of engaging with African material culture and restitution of objects to their places of origin. The recent endorsement by French President Emmanuel Macron for the return of 26 art objects to Benin reflects a growing momentum in repatriation efforts of looted objects in colonial Africa. While the moral question of returning looted items seems indisputable, the question remains of where these objects will live, how they will be cared for, and accessed by the public. The case of the J.H. Kwabena Nketia Archives presented here, though not comparable in terms of care conditions and provenance of objects, pose relevant questions: rather than lamenting the lack or substandard infrastructures for care of material heritage, how do we promote a culture of collective care, increase professional standards, and promote resource sharing from a place of respect and recognition of cultural ownership?

The challenges faced by audio-visual archives in Africa should not relegate collections of African materials to American and European universities, out of the reach of many scholars and students from their countries of origin. Archivists recognize that the location of these materials is as important as their preservation for they contain "vital elements of our collective memory, determining our achievements over the years, documenting our past, present and determining our future" (Zinyengere 2008, 37). The work of the scholars at the University of Ghana who have long contributed to the field of music- Amu, Nketia, Collins, etc.... - are best contextualized in the Archives in which their work of knowledge building has cumulative and collaborative effect. This overview of the Nketia Archives' historical formation as well as current challenges and activities is part of the larger effort stemming from the ground up by the very scholars and archivists at the University of Ghana. Advocacy, continued reflection and evaluation, and awareness-raising are as integral to archival work as conducting fieldwork and building facilities for digitization. Stemming from the Greek archeîn, meaning public office, the archive has a commitment to its public - in this case to the Ghanaians and West Africans whose cultural heritage and musical histories are housed here, as in Nketia's vision, to be studied, recorded, preserved, and practiced as living art. As we have hoped to show here, the process of building and maintaining an audio-visual archive in Ghana is closely linked to the larger struggles of nation forming in post-Colonial Africa. 


\section{Bibliography}

Agawu, K. 2016. The African Imagination in Music. New York: Oxford University Press.

Agawu, K. 2003. Representing African Music: Postcolonial Notes, Queries, Positions. New York \& London: Routledge.

APEX Website. http://www.apexghana.org/?page_id=169 [Accessed 7 July. 2019].

Bender, W. 1994. Institutions in the Field of Ethnomusicology Introduce Themselves (XXIII): African Music Archive, Johannes Gutenberg University, Mainz. The World of Music, 36, pp. I55-I57.

Collins, J. 2012. The Introduction of Popular Music Studies to Ghanaian Universities. Journal of the International Association for the Study of Popular Music (IASPM), 2, pp. 34-44.

Mnjama, N. 2010. Preservation and Management of Audiovisual Archives in Botswana. African Journal of Library, Archives and Information Science, 20(2), I39-I48.

Nayeri, F. 2018. Return of African Artifacts Sets a Tricky Precedent for Europe's Museums. The New York Times. Available at: https://nyti.ms/2DNMsmU [Accessed 7 July. 2019].

Nketia, K. 1998. ICAMD NEWSLETTER. Available at https://sites.ualberta.ca/ michaelf/ African\%20Music_Site/ICAMDNEWSLETTER.htm [Accessed 7 July. 2019].

Nketia, K. 2016. Reinstating Traditional Music in Contemporary Contexts: Reminiscences of a Nonagenarian's Lifelong Encounters with the Musical Traditions of Africa. AkropongAkuapem: Regnum Africa Publications.

Nketia, K. 1994. Generative Processes in Seperewa Music, in: To the Four Corners: A Festschrift in Honor of Rose Brandel. Harmonie Park Press, Pp. 17-I5I.

Sarr, F., Savoy, B. 2018. The Restitution of African Cultural Heritage: Toward a New Relational Ethics. France: Ministere de la Culture.

Sigauke, D, Nengomasha, C. (2012). Challenges and Prospects Facing the Digitization of Historical Records for Their Preservation within the National Archives of Zimbabwe. In: Second International Conference on African Digital Libraries and Archives. Johannesburg: University of Witwatersrand, PP. I-I5.

Zinyengere, I. 2008. African Audio-Visual Archives: Bleak or Bright Future A Case Study of the Situation at the National Archives of Zimbabwe. International Preservation News, 46, pp. 37-4I. 